\title{
Campylobacter infection in a cohort of rural children in Moramanga, Madagascar
}

\author{
Rindra Vatosoa Randremanana ${ }^{1 *}$, Frédérique Randrianirina ${ }^{2}$, Philippe Sabatier ${ }^{3}$, Hanitra Clara Rakotonirina ${ }^{2}$, \\ Arthur Randriamanantena', Iony Manitra Razanajatovo ${ }^{4}$, Rila Ratovoson ${ }^{1}$ and Vincent Richard ${ }^{5}$
}

\begin{abstract}
Background: Campylobacter infection is the most common cause of bacterial gastroenteritis in developing countries, including Madagascar. Reports of pathogenicity have not been consistent and repeated exposures over time seem to lead to the development of protective immunity in developing areas. We conducted this study to support evidence for these hypotheses by exploring the association between infection and age, the reoccurrence of infection and the pathogenicity of Campylobacter.
\end{abstract}

Methods: We carried out a community-based longitudinal study of children under the age of 24 months in two rural villages in Moramanga, Madagascar. Children were visited twice a week and a stool specimen was collected in cases of diarrhoea. Stools specimens were collected bimonthly from all children enrolled, regardless of symptoms. Children were followed-up until the age of 36 months.

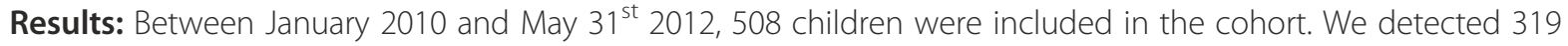
episodes of Campylobacter infection in total, and $43.3 \%(n=220)$ of the children had at least one episode of intestinal Campylobacter infection. The rate of Campylobacter isolation from stool specimens was 9.3\%. The annual incidence rate for symptomatic Campylobacter infection was 0.05 episodes/child. The probability of Campylobacter infection was highest between the ages of six and 23 months. Taking children under six months of age as the reference group, the age-specific odds ratio for the association was 5.0 (95\% Cl: 2.9-8.6) for children aged six to 11 months, 5.7 (95\% Cl: 3.3-10.0) for children aged 12 to 17 months and 3.3 (95\% Cl: 1.8-5.8) for children aged 18 to 23 months. A second episode of infection occurred 63 days after the first episode in children with primary infections, and after 137 days in children with multiple infections $(p<0.01)$. First episodes of Campylobacter infection were associated with diarrhoea (odds ratio $=16.1 ; 95 \%$ Cl: 1.8-140.8).

Conclusion: Our findings suggest that protective immunity to Campylobacter may be acquired over time, following repeated exposures. However, Campylobacter infection prevention measures should be reinforced in the first year of life, as this age seems to be associated with the highest risk of diarrhoea during Campylobacter infection.

Keywords: Campylobacter infection, Cohort study, Diarrhoea, Rural area, Madagascar

\section{Background}

Although, diarrhoea-related mortality is decreasing worldwide since the introduction of oral rehydration therapy, it remains high. In Africa, the estimated annual reduction of diarrhoeal deaths since 2000 was about $4 \%$ per year [1]. In total 3.6 million children each year die before reaching their fifth birthday in Africa, and diarrhoeal disease

\footnotetext{
* Correspondence: rrandrem@pasteur.mg

'Unité Epidémiologie - Institut Pasteur de Madagascar, BP 1274, Antananarivo 101, Madagascar

Full list of author information is available at the end of the article
}

accounts for $11 \%$ of these deaths [1]. Disease morbidity and the incidence of diarrhoea in particular, are declining more modestly [2]. The importance of pathogens such as rotavirus and Escherichia coli in the aetiology of severe childhood diarrhoea in developing countries is well recognised [3,4]. However the role of Campylobacter is not well understood either in the community setting or in hospitalised subjects and outpatients.

The epidemiological features of Campylobacter infection differ between developed and developing countries. Campylobacter is endemic to developing countries, where

\section{Biomed Central}

(C) 2014 Randremanana et al.; licensee BioMed Central Ltd. This is an Open Access article distributed under the terms of the Creative Commons Attribution License (http://creativecommons.org/licenses/by/2.0), which permits unrestricted use, distribution, and reproduction in any medium, provided the original work is properly credited. 
it is, one of the most frequently isolated bacteria from both diarrhoeic and non-diarrhoeic children [5]. Current estimates of the proportion of diarrhoea cases attributable to Campylobacter infection are derived from a small number of studies, but it is believed to be high, between 5 and $20 \%$ [5]. A case-control study for diarrhoea was conducted in 14 districts of Madagascar in 2008 in children underfive, by the Pasteur Institute of Madagascar [6]. Its findings suggested that Campylobacter was the second most frequently isolated enteropathogen, after parasites, in children under the age of five years, with a prevalence of 9.7\%. However, its frequency did not differ between cases and control subjects.

Many studies have suggested that the development of protective immunity in children from developing countries may account for the high rates of asymptomatic Campylobacter infection and for the decrease in the proportion of infected subjects presenting illness with increasing age $[7,8]$. Campylobacter isolation rates are highest during the first two years of life and appear to decline with age $[5,9]$. The development of immunity might also affect the recurrence of infection. Immunity following a first episode of campylobacteriosis might decrease the risk of subsequent events, which might also vary over time and with patient characteristics [10].

In 2008, the cross-sectional study [6] conducted in Malagasy children under-five have not found an association between Campylobacter infection and occurrence of diarrhoea. Thus, we investigated the pathogenicity of Campylobacter through a cohort study and assessed the hypothesis of the development of immunity after Campylobacter infection in Madagascar. We conducted the study in young children under the age of 36 months, known as the age at higher risk of Campylobacter infection.

\section{Methods}

\section{Setting and study population}

This study was conducted in the low-income rural areas of Befotsy and Ampitambe, Moramanga, in the middle of the eastern region of Madagascar. These two villages were the pilot areas of the Health and Demographic Surveillance Site of Moramanga (HDSS Moramanga) and were investigated during the case-control study carried out in 2008 [6]. The highest prevalence of Campylobacter infection in children with diarrhoea was found in the district of Moramanga (20.7\%). The prevalence of Campylobacter was 20\% in Befotsy and 10\% in Ampitambe. The local population is 4231 inhabitants, most of whom are engaged in agricultural activities. The 1006 households lack basic sanitary facilities, use water from the river or a traditional well for drinking and often have free-range domestic chickens at home; the risk of faecal contamination of the environment is therefore likely to be high.

\section{Cohort enrolment}

We used data from HDSS Moramanga, in which longitudinal demographic surveillance was carried out on the population of four communities in the district of Moramanga. The HDSS Moramanga conducted a doorto-door census, and collected demographic data and data for each individual household in the two villages at a given time point (water supply, goods, ownership of animals, etc...). Children under the age of 24 months living in either of the two villages were eligible for enrolment in this study. An open cohort of children enrolled before the age of 24 months was followed up from January 2010 to May 2012. All the children were monitored until the age of 36 months. Children who moved within the study area were followed up at their new homes, whereas those who moved outside the study area were withdrawn from the study. On enrolment, an interview was conducted with one of the child's parents, to obtain information about the child, including breastfeeding and nutritional status. Each of the children enrolled provided a stool specimen for the isolation of Campylobacter spp. Enrolment continued throughout the study, for new infants born into a household and for young children moving into the village.

\section{Surveillance activities \\ Twice a week diarrhoeal surveillance}

From the day of enrolment in the study until 36 months of age, a study physician and a locally recruited community health worker ( $\mathrm{CHW}$ ) visited each of the children twice a week at their homes. The children's mothers were asked about any episodes of diarrhoea since the last visit. If a child had diarrhoeal illness, the physician carried out clinical and anthropometric examinations, collected a stool sample for Campylobacter culture and provided oral rehydration therapy and/or other treatment if indicated. Treatment was given in accordance with Ministry of Health guidelines. Antimicrobial treatment was provided if diarrhoea was associated with fever or blood/mucus in the stools. A pictorial diarrhoea diary was given to the mothers of children with diarrhoea, for recording the number of bowel movements and the consistency of the faeces, from the first day of diarrhoea until its cessation. Movements of children to areas outside the study area, deaths and other losses to follow-up were recorded by the $\mathrm{CHW}$ during the twice a week visits.

\section{Bimonthly surveillance}

We also carried out a cross-sectional surveillance. All children included in the cohort, regardless of their history of diarrhoea, were surveyed once every two months (60 days), with the collection of a stool specimen for Campylobacter isolation. In these surveys, weight and length/ height data were also collected. This cross-sectional study 
provided us with data on asymptomatic Campylobacter infection.

These surveillance activities were performed for the purposes of this study only.

\section{Definitions}

- A day with diarrhoea was defined as a 24-hour period in which three or more loose stools taking the form of the container or any number of stools containing blood were obtained [11]. For small, exclusively breastfed children, if the stools were not bloody, diarrhoea was defined as an increase in the frequency or a reduction of the consistency of the stools with respect to what the mother considered normal for her child.

- Episodes of diarrhoeal illness were defined using a minimum three-day diarrhoea-free gap to mark the beginning of a new episode.

- Campylobacter infection was defined as symptomatic if Campylobacter was isolated from diarrhoeal stools or within a period of five days before and after an episode of diarrhoea.

- Campylobacter infection was defined as asymptomatic if there were at least five consecutive symptom-free days before and after the isolation of Campylobacter from faeces.

- The days at risk included the three-day period following the occurrence of an episode of diarrhoea.

- Primary Campylobacter infection was defined as the first isolation of Campylobacter from a stool specimen collected during enrolment, or at the twice a week or bimonthly surveillance visits, from a child enrolled within 28 days of birth.

- Multiple Campylobacter infections were defined as the isolation of Campylobacter from a stool specimen collected during enrolment, or at the twice a week or bimonthly surveillance visits, from a child enrolled after the age of 28 days.

\section{Microbiological analyses}

For the isolation of Campylobacter spp., we cultured fresh faecal specimens from children with and without diarrhoea directly in the field on selective agar plates (Karmali). Plates were incubated at $37^{\circ} \mathrm{C}$ under microaerophilic conditions (Campygen, Oxoid France) for 48 to 72 hours. The identification of Campylobacter isolates was confirmed with the Campy dry spot kit, a haemagglutination test from Oxoid (England), as recommended by the manufacturer. We differentiated between Campylobacter jejuni (C. jejuni), Campylobacter coli (C. coli) and other species by the multiplex polymerase chain reaction (PCR) method [12]. This differentiation was conducted on 271 samples of Campylobacter isolates selected at random.

\section{Data analysis}

We analysed data from $19^{\text {th }}$ January 2010 until $31^{\text {st }}$ May 2012. Person-time at risk was calculated as the observed number of days at risk between episodes. Incidence rates were calculated by dividing the number of episodes by the number of child-years of observation. We estimated the incidence rates for diarrhoea and symptomatic infection. Children were assigned to age groups: 0 to 5 months, 6 to 11 months, 12 to 17 months, 18 to 23 months, 24 to 29 months and 30 to 36 months. This classification of age group was chosen in accordance with our hypothesis that exposure and infection risk vary with age.

Anthropometric measurements were transformed into weight-for-height/length, height/length-for-age and weightfor-age Z scores based on WHO standard reference population. Stunting, wasting and underweight were defined as height/length-for-age, weight-for-height/length and weightfor-age less than -2 standard-deviations from the reference standards for children of the same age and sex, respectively [13].

\section{Association between infection and age At the time of enrolment}

The Chi-squared test was used to measure associations between Campylobacter infection and age group at the time of enrolment. If a significant result was obtained by the Chi-squared test, we assessed the strength of association between Campylobacter infection and age group at the time of enrolment by logistic regression. The unit of analysis was the individual child. Data collected at the time of enrolment were used, with age group considered as the explanatory variable and the infection status of the faecal specimen as the outcome.

\section{During follow-up}

During follow-up, the association of Campylobacter infection and symptomatic Campylobacter infection with age group was assessed with a logistic mixed regression model. The outcome variable was Campylobacter infection or symptomatic Campylobacter infection status, and age group was the main explanatory variable. For the two analyses, we incorporated socioeconomic and household data collected at the time of enrolment, nutritional status data obtained during enrolment and followup as potential confounding variables. We included in the mixed models all potential confounding variables with a $p$-value $<0.2$ in the univariate analyses. We then used backward elimination to identify confounding variables for inclusion in the final model. A Wald Chisquared test was used to assess the significance of each of the variables tested and odds ratios were calculated to 
quantify their effects. The follow-up visits for a given child were not statistically independent entities. We therefore took into account the correlation between repeated observations for each individual, between multiple children living in the same household and in the same village. Thus, for the two mixed models, we added each observation for each child, household and village as a random effect. The use of a random effect made it possible to adjust for the correlation between data obtained from the same individual, the same household or the same village and to measure the variability between these data.

The unit of analysis was the individual visit, with the collection of a stool sample, for investigations of the relationship between Campylobacter infection and age. For analysis of the relationship between symptomatic Campylobacter infection and age, we considered each visit at which a diarrhoeal stool sample was obtained (diarrhoeal episode) as the unit of analysis. We took the 0-5 months age group as the reference group.

Data for Campylobacter infection status (overall infection, symptomatic infection) were obtained at the time of enrolment, and at the twice a week and bimonthly surveillance visits.

\section{Pathogenicity of Campylobacter}

The association between Campylobacter infection and diarrhoeal episodes was investigated with logistic regression models. This analysis was performed on newborns enrolled within 28 days of birth. Children with diarrhoea were considered as the outcome, with Campylobacter infection as the explanatory variable.

\section{Recurrent episodes}

Survival analysis was used to assess the time to recurrent episodes of Campylobacter in children with primary infection and those with multiple infection. We used logrank tests to compare the two Kaplan-Meier survival curves. We used Cox proportional hazard models to assess the extent to which the timing of recurrent episodes could be explained by potential confounders. Time to event was estimated as the interval between the first and second episodes of infection.

Data were analysed with $\mathrm{R}$ software version 2.12.1 ( $\mathrm{R}$ Development Core Team (2007). For all statistical tests, a $p$-value below 0.05 was considered statistically significant.

\section{Ethics}

Written informed consent was obtained from the parent or guardian of each child before enrolment. The study was approved by the National Ethics Committee of the Ministry of Health of Madagascar (Number 002-CE/ MINSAN - 01/13/2012).

\section{Results}

We recruited 210 children at the start of the study. Thereafter, 68 new births, 54 immigrants to the study and 176 children included after the age of 28 days were enrolled. The mean age of children at the start of the study was 11.7 months (standard deviation: 7.4; range: 0.2-23 months; median: 11.6 months). During the observation period, four children died from causes other than diarrhoea during their first year of life and 68 (13.4\%) dropped out of the study due to a withdrawal of consent $(22 / 508)$ or migration out of the study area (46/508). The study population comprised 508 children, who were followed for a total of 256,366 child-days (702.4 childyears). The median follow-up time was 505.7 days (interquartile range [IQR]: 373 days). The cohort of 508 children consisted of 259 girls and 249 boys (male/female ratio $=0.9$ ). The characteristics of the cohort children were shown in Table 1.

Over the two 2-year study period, 3424 stool samples were tested for Campylobacter. In total, 2965 (87\%) of these samples were collected from children without diarrhoea during the cross-sectional survey, which was conducted at two-month intervals. The rate of Campylobacter isolation from all samples was 9.3\% (319/3424): 8.9\% (41/ 459) from diarrhoeic samples and $9.4 \%$ (278/2965) in non-diarrhoeic samples. Overall, 43.3\% (220/508) of children had at least one Campylobacter infection; 16.4\% (36/ 220 ) of the infected children had diarrhoea and 32.3\% (71/ 220) had more than one episode of Campylobacter infection. Overall, 13.9\% (71/508) of all children had more than one episode of infection. Identification to the species level was carried out for 271 of the 319 Campylobacter isolates: 190 (70.1\%) were C. jejuni, 64 (23.6\%) were C. coli and 17 (6.3\%) belonged to other species. There were no statistically significant difference between the isolation rate of $C$. jejuni and C. coli from diarrhoeal and non-diarrhoeal samples ( $\mathrm{p}=0.16$, Chi-squared test). We found that children infected with $C$. jejuni were likely to have subsequent infection than those infected with C.coli ( $\mathrm{p}=0.002$, Chisquared test): $4.7 \%$ (3/64) of children infected with $C$. coli and $21.6 \%(39 / 180)$ of those infected with $C$. jejuni had subsequent infection. Campylobacter isolation rates from diarrhoeic and non-diarrhoeic samples, by age group, are shown in Table 2.

At the time of enrolment, $6.3 \%(n=32)$ of the children were already infected with Campylobacter: 6.2\% (2/32) were symptomatic and the remaining (30/32) children were asymptomatic. The prevalence of Campylobacter infection, by age group, at the time of enrolment was $4.6 \%(17 / 369)$ for children under 12 months of age and $10.8 \%(15 / 139)$ for children aged 12 months or older. The frequency of Campylobacter infection at the time of enrolment differed significantly between age groups (Chi-squared test, $p<0.001$ ). The age-specific odds ratios 
Table 1 Characteristics of the cohort children during a 28-month longitudinal community study of Campylobacter infection, Moramanga, 2010-2012

\begin{tabular}{llcc}
\hline $\begin{array}{llc}\text { Characteristics } \\
\text { Demographic data } \mathbf{n}=\mathbf{5 0 8}\end{array}$ & & N & (\%) \\
\hline Sex & Male & & \\
& Female & 249 & $(49.0)$ \\
Age group (months) & $<6$ & 259 & $(51.0)$ \\
& $6-11$ & 295 & $(58.1)$ \\
& $12-17$ & 74 & $(14.5)$ \\
& $18-23$ & 64 & $(12.6)$ \\
Nutritional status data $\mathbf{n}=\mathbf{5 0 6}$ & 75 & $(14.7)$ \\
Stunting & Yes & & \\
& No & 151 & $(29.8)$ \\
Underweight & Yes & 355 & $(70.2)$ \\
& No & 46 & $(9.1)$ \\
Wasting & Yes & 460 & $(81.9)$ \\
& No & 5 & $(0.9)$ \\
& & 501 & (99.1)
\end{tabular}

Households data $n=439$

Number of persons/room (mean \pm SD) $3.7( \pm 1.7)$

Floor

Concrete 271

Cooking area

Mud

Shower area

Latrin

Domestic animals

Livestock \#

Fowl§

Goodsf

Source of drinking water

Water drinking storage

Yes

Yes

No

Yes

No

Yes

No

Yes

No

Yes

No

Yes

No

Tubewell, borehole

\section{Surface waters}

Protected

Unprotected

Yes

No

Data about mother $n=416$

Age (years) (mean \pm SD) $28.3( \pm 9)$

Maternal education

Primary

Secondary
Table 1 Characteristics of the cohort children during a 28-month longitudinal community study of Campylobacter infection, Moramanga, 2010-2012 (Continued)

$\begin{array}{lcc}\text { Superior } & 4 & (0.9) \\ \text { No education } & 27 & (6.5)\end{array}$

SD: standard-deviation.

\#Ownership of one of the following: cow, ox, sheep, pig, rabbit.

§Ownership of one of the following: chicken, duck, goose.

$£$ Ownership of one of the following: radio, television, bicycle, sewing machine, mobile phone, rice fields, house.

for Campylobacter infection at the time of enrolment were 8.6 (95\% confidence interval [CI]: 3.0-24.1), 5.9 (95\% CI:1.9-18.3), 5.7 (1.9-17.2) for the 6-11 month, 12-17 month and 18-23 month age groups, respectively.

The probability of infection during follow-up varied with age. In the logistic mixed model, taking children under six months of age as the reference group, the odds of being infected with Campylobacter were five times higher in children aged between six and 18 months, the odds ratio were 5 (95\% CI: 2.9-8.6) for children aged six to 11 months and 5.7 (95\% CI: 3.3-10) for those aged 12 to 17 months (Table 3 ). The association for living in a household that owned livestock (versus living in a household that did not own livestock) was of borderline significance (odds ratio: 1.3; 95\% CI: 1.0-1.7). The variables with a $p$-value below 0.2 included in the mixed regression model were the construction of a floor, the ownership of goods, domestic animals, livestock and the availability of toilets. An additional file shows the result of univariate analysis in more detail [see Additional file 1].

Antimicrobial treatments were given to children with diarrhoea who had fever and to children with blood or mucus in their faeces. Antimicrobial treatment was given to $18.5 \%(85 / 459)$ of patients with diarrhoeal episodes due to fever and to $17.8 \%$ due to the presence of blood or mucus in the faeces $(3.1 \%$ for blood and $14.8 \%$ for mucus in the faeces). Mild dehydration was observed in four episodes of diarrhoea.

We observed 475 diarrhoeal episodes with a median duration of 4.5 days (IQR: 5 days), resulting in an annual incidence rate of 0.7 episodes/child (95\% CI: 0.7-0.8 episodes/child). We were able to collect stool samples for 96.6\% (459/475) of all diarrhoeal episodes. Overall, 53.7\% $(n=273)$ of the children presented at least one episode of diarrhoea during the observation period. The highest incidence rates were obtained for children under the age of 12 months. The annual incidence was 0.8 episodes/ child (95\% CI: $0.7-0.9$ episodes/child) in children aged 0 to 11 months and 0.5 episodes/child (95\% CI: 0-0.6 episodes/ child) for children over the age of 12 months.

The overall annual incidence of symptomatic Campylobacter infections was 0.05 episodes/child. The median duration of symptomatic Campylobacter infection 
Table 2 Rate of isolation of enteric Campylobacter from diarrhoeic and non-diarrhoeic samples, Moramanga, 2010-2012

\begin{tabular}{|c|c|c|c|c|c|c|}
\hline \multirow[b]{3}{*}{ Age group } & \multirow[b]{3}{*}{$\begin{array}{l}\text { Child-days } \\
\text { at risk }\end{array}$} & \multicolumn{4}{|c|}{ Number of positive samples } & \multirow[b]{3}{*}{$\begin{array}{l}\text { Number of } \\
\text { infections }\end{array}$} \\
\hline & & \multicolumn{2}{|c|}{ Diarrhoeal stools } & \multicolumn{2}{|c|}{ Non-diarrhoeal stools } & \\
\hline & & $\begin{array}{l}\text { Number of } \\
\text { episodes }\end{array}$ & $\begin{array}{c}\text { Number } \\
\text { positive (\%) }\end{array}$ & $\begin{array}{l}\text { Number } \\
\text { of tests }\end{array}$ & $\begin{array}{c}\text { Number } \\
\text { positive (\%) }\end{array}$ & \\
\hline $0-5$ months & 27,616 & 64 & $4(6.2)$ & 564 & $14(2.5)$ & 18 \\
\hline 6-11 months & 77,208 & 171 & $16(9.3)$ & 641 & $93(14.5)$ & 109 \\
\hline 12-17 months & 68,184 & 102 & $10(9.8)$ & 557 & $90(16.1)$ & 100 \\
\hline 18-23 months & 25,146 & 64 & $6(9.4)$ & 535 & $46(8.6)$ & 52 \\
\hline 24-29 months & 30,859 & 40 & $4(10.0)$ & 399 & $22(5.5)$ & 26 \\
\hline 30-36 months & 27,353 & 18 & $1(5.5)$ & 269 & $13(4.8)$ & 14 \\
\hline Total & 256,366 & 459 & $41(8.9)$ & 2965 & $278(9.4)$ & 319 \\
\hline
\end{tabular}

was five days, with an IQR of 4.3 days. The mean age for symptomatic Campylobacter infection was 13.8 months (standard deviation: 7.1; range: 2.7-33.8 months; median: 11.8 months). Among the children with diarrhoea, 13.2\% (36/273) excreted Campylobacter and 16.7\% (6/36) received antimicrobial treatments. The frequency of symptomatic Campylobacter infections did not differ between age groups ( $p=0.3$, Wald $z$-statistic test).

Campylobacter was isolated from 201(39.6\%) asymptomatic children. The mean age for asymptomatic Campylobacter infection was 14.7 months (standard deviation: 7; range: 1.3-35.2 months; median: 13 months).

There was a statistically significant association between Campylobacter primary infection and diarrhoea ( $p<0.001$, Wald $z$-statistics test). In the birth cohort of 64 children, the odds ratio for shedding Campylobacter for the first time among children with diarrhoea was 16.1 (95\% CI: 1.8-140.8), taking children without diarrhoea as the reference group.

Infection recurred more rapidly in children with primary infections than in those with multiple infections: $25 \%$ of children with primary infections had their second infection episode 63 days after the first episode, whereas the second episode occurred after 317 days after the first episode in children with multiple infections $(p<0.01$, $\log$-rank test). Figure 1 shows the survival curves for recurrent infection over time for the two groups. We found that children with primary infection living in a household that have mud flooring was 6.1 times at risk (hazard-ratio: 6.1, CI 95\%: 1.4-25.5) to have recurrent infections more rapidly than those living in household with floor made with concrete materials (cement, tiles).

\section{Discussion}

To our knowledge, this is the first cohort study on diarrhoea in children in Madagascar.

Our results provide an indication of the role of the immunity on the occurrence of Campylobacter infection in children in Moramanga, as we observed an age-related decrease in infection rates and the time to recurrence was shorter in children with primary infections than in those with multiple infections. Our data also suggest that the first Campylobacter infection was associated to diarrhoea.

We found an association between age group and infection, as reported in other developing countries [14,15],

Table 3 Associations of Campylobacter infection with age group during follow-up, mixed logistic regression model, Moramanga, 2010-2012

\begin{tabular}{|c|c|c|c|c|c|}
\hline \multirow[t]{2}{*}{ Confounding variables } & & \multicolumn{2}{|c|}{ Presence of Campylobacter } & \multirow[t]{2}{*}{ Crude OR } & \multirow[t]{2}{*}{ Adjusted OR* } \\
\hline & & Yes & No & & \\
\hline \multirow[t]{6}{*}{ Age group } & $<6$ months & $16(3.0) \S$ & $521(97.0) \S$ & Reference & Reference \\
\hline & 6-11 months & $94(13.1)$ & $619(86.9)$ & $4.9(2.7-8.9) \dagger$ & $5.0(2.9-8.6) \dagger$ \\
\hline & 12-17 months & $90(15.0)$ & $509(85.0)$ & $6.0(3.3-10.9)$ & $5.7(3.3-10.0)$ \\
\hline & $18-23$ months & $51(9.0)$ & $514(91.0)$ & $3.3(1.8-5.9)$ & $3.3(1.8-5.8)$ \\
\hline & 24-29 months & $25(6.0)$ & $396(94.0)$ & $2.2(1.2-4.0)$ & $2.1(1.1-4.0)$ \\
\hline & 30-36 months & $14(4.9)$ & $272(95.1)$ & $1.8(0.8-3.9)$ & $1.6(0.8-3.4)$ \\
\hline Total & & 290 & 2831 & & \\
\hline
\end{tabular}

tNumbers in brackets, 95\% confidence interval; OR: odds ratio.

$\S$ Numbers in brackets, percentage.

*Adjusted for the ownership of livestock, mixed models were generated from 3121 observations. 


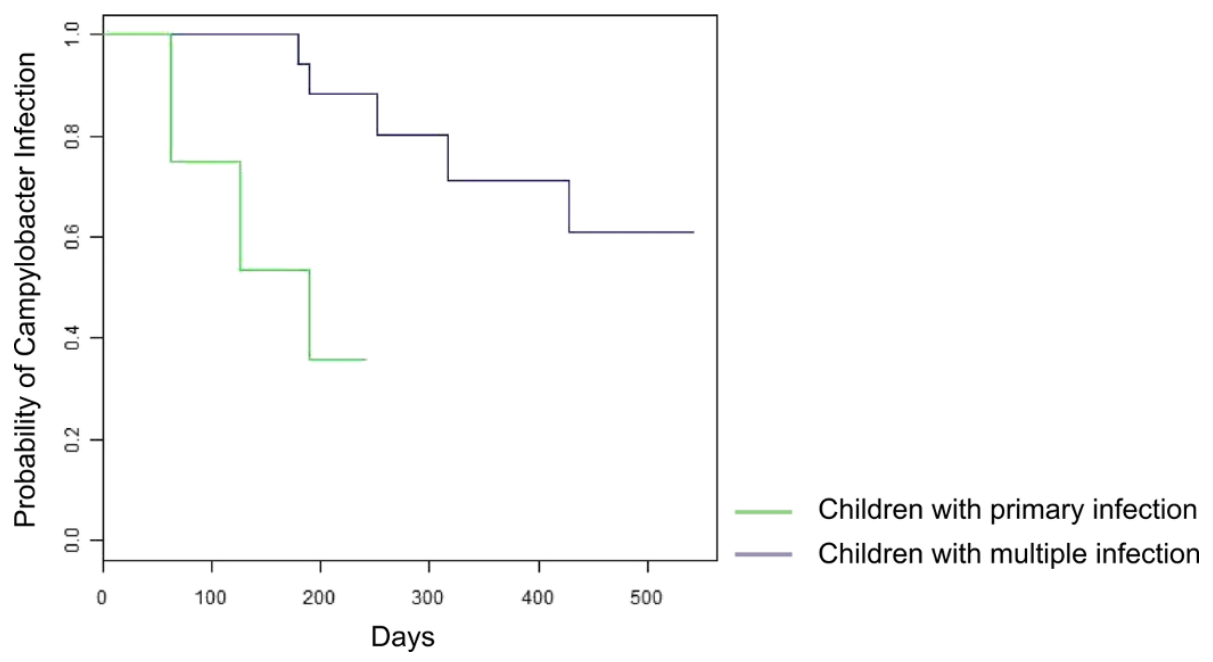

Figure 1 Survival curves for Campylobacter infections in children with primary and multiple infections, Moramanga $2010-2012$.

with infection rates increasing up to the age of six months and then decreasing after 30 months. In our cohort of children, immunity seemed to decrease the probability of acquiring infection in response to further exposures over time [16,17]. The shorter time to recurrence of infection in children with primary infection may reflect the immature and naive nature of the immune system in this group. The immune system is known to be immature at birth, with microbial colonization of the intestine playing a role in the maturation of the immune cell response $[18,19]$. Repeated exposures may be required to achieve immunity. Prior immunity has also been demonstrated to be important for protection against Campylobacter in other studies [20]. The first primary infection in our study occurred at the age of five months, suggesting a contribution of antibody transfer from the mother during the first five months of life. Susceptibility to Campylobacter infection in early infancy may thus be reduced by the acquisition of passive immunity from placentally transferred antibodies from immune mothers [17]. A previous study conducted in the Central African Republic also suggested a protective role for maternal antibodies. Children who had Campylobacter infections during the first six months of life had significantly fewer anti-flagellum antibodies at birth than those who did not have Campylobacter infections during this period [21,22]. Breastfeeding may also affect the development of immunity during early infancy; data about breastfeeding were not available during the follow-up period. We found that for children with primary infection, living in a household that have mud flooring is associated with an increased risk of having recurrent episodes. A mud flooring habitation may be considered as a proxy of a low socio-economic status of the household, human Campylobacter infection was already reported to be associated with poverty [15]. Our observation may also suggest that there is a risk of Campylobacter transmission in environments where there may be a poor hygiene conditions.

We conclude that the first Campylobacter infection was pathogenic. An analysis performed in a subset of the cohort, in newborns enrolled during the first 28 days of life, corroborated this finding. Reports of the pathogenicity of Campylobacter in different studies from around the developing world have not been consistent $[7,8,15]$. The development of diarrhoea during Campylobacter infection may depend on bacterial virulence and host susceptibility factors [23], and strains of Campylobacter may differ in pathogenicity. There may also be animal host-adapted genotypes that never or rarely cause diarrhoea in humans [24]. Despite the many studies carried out on Campylobacter, we still need to elucidate the mechanism by which Campylobacter causes diarrhoea in humans and its interaction with the human immune system.

Our data showed that species-specific immunity is less likely to occur, however it is difficult to conclude about species-specific resistance to reinfection as it is possible that there was a reinfection with the same species but with strains having different antigenic properties, thus immunity is not effective. Strain and serotype differences might have also an importance in protective immunity; immunity in human seems to be serotype-specific [25], neither genotypic nor serotyping analysis could not be performed in this study. In addition, host-specific intestinal microbiota composition may play also an important role in the proper development of immune system. Mechanisms underlying colonization resistance against Campylobacter infection are multifactorial. Repeated exposure is required for the generation of acquired immunity, but exposure to different strains of Campylobacter and 
overwhelming challenge may overcome immunity [21]. In developing countries, repeated exposure may subvert or suppress immune responses rather than leading to protection [26].

The rate of Campylobacter isolation in our study area was $9.3 \%$ and the annual incidence of symptomatic infection was 0.05 episodes/child. The rate of isolation of Campylobacter was lower than that reported for Peruvian children [15] but higher than that estimated for an Egyptian cohort [8]. However, the annual incidence of symptomatic infection in our study was only one tenth that reported in Peru [15], Mexico [7] and Egypt [8]. We documented Campylobacter in $13.2 \%$ of children with diarrhoea; this proportion has been estimated at $15.9 \%$ in the Central African Republic [21], 3.3\% in Djibouti [27] and $0.8 \%$ in Guinea-Bissau [28]. These differences may reflect differences in environment, context and study design between settings. In addition, technical difficulties in the isolation of Campylobacter species in developing countries, due to their fastidious growth requirements and/or the relative insensitivity of culture techniques, may influence detection rates [29]. We do not have data on the presence of other bacterial or parasitic pathogens, thus we are therefore unable to ascertain which pathogen is the causative agent of the diarrhoeal episode. Assessing coinfections were of interest as the presence of any enteric pathogen may modulate the effect of other enteropathogens during concurrent infection to modify the clinical expression. During this study, stool samples have been stored for future testing.

In this study, we followed up a small sample of children included before the age of 28 days. An epidemiological study on this birth cohort might provide a better assessment of the role of immunity in determining the occurrence of infection.

We have not included in the logistic mixed model a random-effect that account for clustering through time. This could have an impact on our results. However, the individual random-effect might already account for this autocorrelation over time even if the time is not explicitly represented. Visits were made at regular intervals and we have not visited many children at very short intervals.

\section{Conclusion}

This study suggests the role of prior immunity and repeated exposures on the occurrence of Campylobacter infection in children in the rural areas of Befotsy and Ampitambe, like in the other parts of the developing world. The association between infection and diarrhoea during the first year of life, the effect of the quality housing and the hygiene practices on the occurrence of recurrent episodes highlight the need for greater awareness of diarrhoeal disease prevention measures in infants and the importance of controlling Campylobacter infection. Prioritising interventions, such as those that may improve hygiene-related behaviors and/or the development of vaccines for prevalent Campylobacter serotypes, might have an impact on diarrhoeal illnesses in the developing world. The Moramanga HDSS constitutes a potential research platform for Campylobacter infection studies and vaccine trials.

\section{Additional file}

Additional file 1: Univariate analysis of risk factors for Campylobacter infection, Moramanga, 2010-2012.

\section{Competing interests}

The authors have no competing interests to declare.

\section{Authors' contributions}

RVR conceived and co-ordinated the study, performed the statistical analysis and drafted the manuscript; FR participated in the design of the study and carried out the biological analysis of stool samples; PS participated in the design of the study and was involved in revising the manuscript critically for important intellectual content; HCR performed the PCR analysis; AR performed the field study and participated in the coordination of the study; IMR performed the PCR analysis; RR participated in the design of the study and the collection of data; VR participated in the design of the study and was involved in revising the manuscript critically for important intellectual content. All authors have read and approved the final manuscript.

\section{Acknowledgments}

We thank Corine Vincent, Florian Girond, Renaud Lancelot and Dominique Bicout for their suggestions and help, the staff of the Epidemiology Unit and the Centre de Biologie Clinique of the Institut Pasteur of Madagascar. We would also like to thank the local community health workers and the people of the Fokontany of Befotsy and Ampitambe for their participation.

\section{Funding}

This work was supported by the Institut Pasteur de Madagascar [322/IPM DAF/Hn/09/02/2010], Cooperation française - projet MADES [N²0104602/CC/ $\mathrm{VdRC}$ ] and Fondation Total. The funding organisations had no role in study design, data collection and analysis, the decision to publish, or the preparation of the manuscript.

\section{Author details}

${ }^{1}$ Unité Epidémiologie - Institut Pasteur de Madagascar, BP 1274, Antananarivo 101, Madagascar. ${ }^{2}$ Centre de Biologie Clinique - Institut Pasteur de Madagascar, BP 1274, Antananarivo 101, Madagascar. ${ }^{3}$ Equipe Environnement et Prédiction de la Santé des Populations- TIMC-IMAG, UMR 5525, CNRS-UJFVetAgroSup, 1, avenue Bourgelat, F 69280 Marcy l'Etoile, Lyon, France. ${ }^{4}$ Laboratoire d'Epidémio-surveillance-Institut Pasteur de Madagascar, BP 1274, Antananarivo 101, Madagascar. ${ }^{5}$ Unité Epidémiologie - Institut Pasteur de Dakar, Dakar, Sénégal.

Received: 5 April 2013 Accepted: 1 July 2014

Published: 5 July 2014

\section{References}

1. Liu L, Johnson HL, Cousens S, Perin J, Lawn JE SS, Rudan I, Campbell H, Cibulskis R, Li M, Mathers C, Black RE, for the Child Health Epidemiology Reference Group of WHO and UNICEF: Global regional and national causes of child mortality: an updated systematic analysis for 2010 with time trends since 2000. Lancet 2012, 379(9832):2151-2161.

2. Fischer Walker CL, Perin J, Aryee MJ, Boschi-Pinto C, Black RE: Diarrhea incidence in low- and middle-income countries in 1990 and 2010: a systematic review. BMC Public Health 2012, 12:220.

3. Gupta SK, Keck J, Ram PK, Crump JA, Miller MA, Mintz ED: Part III. Analysis of data gaps pertaining to enterotoxigenic Escherichia coli infections in 
low and medium human development index countries, 1984-2005. Epidemiol Infect 2008, 136(6):721-738.

4. Cunliffe NA, Ngwira BM, Dove W, Thindwa BD, Turner AM, Broadhead RL, Molyneux ME, Hart CA: Epidemiology of rotavirus infection in children in Blantyre, Malawi, 1997-2007. J Infect Dis 2010, 202(Suppl):S168-S174.

5. Coker AO, Isokpehi RD, Thomas BN, Amisu KO, Obi CL: Human campylobacteriosis in developing countries. Emerg Infect Dis 2002, 8(3):237-244.

6. Randremanana R, Randrianirina F, Gousseff M, Dubois N, Razafindratsimandresy R, Ratsima Hariniana E, Garin B, Randriamanantena A, Rakotonirina HC, Ramparany L, Ramarokoto CE, Rakotomanana F, Ratsitorahina M, Rajatonirina S, Talarmin A, Richard V: Case-control study of the etiology of infant diarrheal disease in 14 districts in Madagascar. PLoS One 2012, 7(9):e44533.

7. Calva JJ, Palacios GMR, Lopez-Vidal AB, Ramos A, Bojalil R: Cohort study of intestinal infection with Campylobacter in Mexican children. Lancet 1988 1:503-506.

8. Rao MR, Naficy AB, SavarinoS J, Abu-Elyazeed R, Wierzba TF, Peruski LF, Abdel-Messih I, Frenck R, Clemens JD: Pathogenicity and convalescent excretion of Campylobacter in rural Egyptian children. Am J Epidemiol 2001, 154(2):166-173.

9. Taylor DN, Echeverria P, Pitarangsi C, Seriwatana J, Bodhidatta L, Blaser MJ: Influence of strain characteristics and immunity on the epidemiology of Campylobacter infections in Thailand. J Clin Microbiol 1988, 26(5):863-868.

10. Arsenault J, Ravel A, Michel P, Berke O, Gosselin P: Do patients with recurrent episodes of campylobacteriosis differ from those with a single disease event? BMC Public Health 2011, 11:32

11. Baqui AH, Black RE, Yunus MD, Hoque ARA, Chowdhury HR, Sack RB: Methodological issues in diarrhoeal diseases epidemiology: definition of diarrhoeal episodes. Int J Epidemiol 1991, 20:1057-1063.

12. Yamazaki-Matsune W, Tagichi M, Seto K, Kawahara R, Kawatsu K, Kumeda Y, Kitazato M, Nukina M, Misawa N, Tsukamoto T: Development of a multiplex PCR assay for identification of Campylobacter coli, Campylobacter fetus, Campylobacter hyointestinalis subsp.hyointestinalis, Campylobacter jejuni, Campylobacter lari and Campylobacter upsaliensis. J Med Microbiol 2007, 56:1467-1473.

13. De O, Garza C, Onyango AW, Rolland-Cachera MF, le Comité de nutrition de la Societé Française de pédiatrie: WHO Growth standard for infants and young children. Arch Pediatr 2009, 16:47-53.

14. Gupta PG, Nair GB, Mondal S, Gupta DN, Sen D, Sikdar SN, Das P, Sarkar RK Ghosh S, Saha NC, Deb BC, Pal SC: Epidemiology of campylobacteriosis in a cohort of rural population near Calcutta. Epidemiol Infect 1991, 106:507-512.

15. Oberhelman RA, Gilman RH, Sheen P, Cordova J, Taylor DN, Zimic M, Meza R, Perez J, LeBron C, Cabrera L, Rodgers FG, Woodward DL, Price LJ: Campylobacter transmission in a Peruvian shantytown: a longitudinal study using strain typing of Campylobacter isolates from chickens and humans in household clusters. J Infect Dis 2002, 187:260-269.

16. Ketley JM: Pathogenesis of enteric infection by Campylobacter. Microbiology 1997, 143(Pt 1):5-21.

17. Havelaar AH, van Pelt W, Ang CW, Wagenaar JA, van Putten JPM, Gross U, Newell DG: Immunity to Campylobacter: its role in risk assessment and epidemiology. Crit Rev Microbiol 2009, 35(1):1-22.

18. Atarashi K, Tanoue T, Shima T, Imaoka A, Kuwahara T, Momose Y, Cheng G, Yamasaki S, Saito T, Ohba Y, Taniguchi T, Takeda K, Hori S, Ivanov II, Umesaki $Y$, Itoh K, Honda K: Induction of colonic regulatory T cells by indigenous Clostridium species. Science 2011, 331(6015):337-341.

19. Gaboriau-Routhiau V, Rakotobe S, Lecuyer E, Mulder I, Lan A, Bridonneau C, Rochet V, Pisi A, De Paepe M, Brandi G, Eberl G, Snel J, Kelly D, CerfBensussan N: The key role of segmented filamentous bacteria in the coordinated maturation of gut helper T cell responses. Immunity 2009, 16(4):677-689. 31.

20. Kirkpatrick BD, Lyon CE, Porter CK, Maue AC, Guerry P, Pierce KK, Carmolli MP, Riddle MS, Larsson CJ, Hawk D, Dill EA, Fingar A, Poly F, Fimlaid KA, Hoq F, Tribble DR: Lack of homologous protection against Campylobacter jejuni CG8421 in a human challenge model. Clin Infect Dis 2013, 57(8):1106-1113.

21. Georges-Courbot MC, Beraud-Cassel A, Gouandjika I, Georges A: Prospective study of enteric Campylobacter infections in children from birth to 6 months in the Central African Republic. J Clin Microbiol 1987, 25(5):836-839.
22. Martin PM, Mathiot J, Ipero J, Kirimat M, Georges AJ, Georges-Courbot MC: Immune response to Campylobacter jejuni and Campylobacter coli in a cohort of children from birth to 2 years of age. Infect Immun 1989, 57(8):2542-2546.

23. Jansenn R, Krogfelt KA, Cawthraw SA, van Pelt W, Wagenaar JA, Owen RJ: Host-pathogen interactions in Campylobacter infections: the host perspective. Clin Microbiol Rev 2008, 21(3):505-518.

24. Manning G, Dowson CG, Bagnall MC, Ahmed IH, West M, Newell DG: Multilocus sequence typing for comparison of veterinary and human isolates of Campylobacter jejuni. Appl Environ Microbiol 2003, 69(11):6370-6379.

25. Islam A, Raghupathy R, Albert MJ: Recombinant PorA, the major outer membrane protein of Campylobacter jejuni provides heterologous protection in an adult mouse intestinal colonization model. Clin Vaccine Immunol 2010, 17:1666-1671.

26. Glennie SJ, Nyirenda M, Williams NA, Heyderman RS: Do multiple concurrent infections in African children cause irreversible immunological damage? Immunology 2012, 135(2):125-132.

27. Mikhall IA, Fox E, Haberberger RL Jr, Ahmed MH, Abatte EA: Epidemiology of bacterial pathogens associated with infectious diarrhoea in Djibouti. J Clin Microbiol 1990, 28:956-961.

28. Molbak K, Wested N, Hojlyng N, Scheutz F, Gottschau A, Aaby P, da Silva APJ: The etiology of early childhood diarrhea: a community-study from Guinea-Bissau. J Infect Dis 1994, 169:581-587.

29. Mason J, Iturriza-Gomara M, O'Brien SJ, Ngwira BM, Dove W, Maiden MC, Cunliffe NA: Campylobacter infection in children in Malawi is common and is frequently associated with enteric virus co-infections. PLOS One 2013, 8(3):e59663.

doi:10.1186/1471-2334-14-372

Cite this article as: Randremanana et al:: Campylobacter infection in a cohort of rural children in Moramanga, Madagascar. BMC Infectious

Diseases 2014 14:372

\section{Submit your next manuscript to BioMed Central and take full advantage of:}

- Convenient online submission

- Thorough peer review

- No space constraints or color figure charges

- Immediate publication on acceptance

- Inclusion in PubMed, CAS, Scopus and Google Scholar

- Research which is freely available for redistribution

Submit your manuscript at www.biomedcentral.com/submit
C) Biomed Central 